\title{
Quantitative and Financial Aspects of Resilience Bonds in the Context of Recursive Insurance Contracts. A Cost Benefit Analysis
}

\author{
Andrea Jonathan PAGANO ${ }^{1 *}$, Francesco ROMAGNOLI ${ }^{2}$, Emanuele VANNUCCI $^{3}$ \\ ${ }^{1,2}$ Institute of Energy Systems and Environment, Riga Technical University, Azenes iela 12/1, Riga, \\ LV-1048, Latvia \\ ${ }^{3}$ Department of Business and Management, Pisa University, Cosimo Ridolfi street 10, Pisa, 56124, Italy
}

\begin{abstract}
It is now well known that the world community must share the risks and hazards deriving from climate change and, more generally, from the environment. At the end of summer 2019, the European Bank for Reconstruction and Development (EBRD) issued the World's first dedicated climate resilience bond and this confirms the thesis according to which financial, social and economic instruments are always most necessary for the development of society and to avoid that natural hazards can, as occurred in the past, cause extremely heavy damage with negative repercussions on every single area of a community. Starting from the characteristics of resilience bonds and reinsurance, the paper seeks to highlight the potential advantages that would derive from a systematic application of recursive contractual instruments (smart contracts). The authors focused on the study of the projection of financial and quantitative data of resilience and catastrophe bonds on the basis of a determined timeline, a fixed insurance premium, mitigation works related and connected to the main contract (insurance). In particular, the study concerns the correlation of the urban implementation of risk mitigation works with the specific catastrophic flood risk. The paper implements a purely economic and social cost-benefit analysis (ACB) in the sense that includes, among others, a public approach and the goal of maximizing social welfare, according to efficiency economic criteria. In a nutshell, the authors highlight as the main result not only the possibility, but also the convenience of the joint and multidisciplinary application of the quantitative method (resilience bonds) to infrastructure resilience.
\end{abstract}

Keywords - Insurance; flood; public administration; quantitative method; resilience; risk mitigation; urban infrastructure

\section{INTRODUCTION}

Preliminarily, using experience from the Italian context, albeit in the broader supranational scenario, it is absolutely essential and at least advisable to carry out a discussion on the methods for stipulating a legal transaction, in particular an insurance contract, with the public administration. This examination allows to verify the operating methods and necessary requirements to outline a possible contract such that, against a fixed premium, it is possible to guarantee the coverage of damages and at the same time the construction of a mitigative infrastructure.

Moreover, the paper outlines the concept of infrastructural resilience.

* Corresponding author.

E-mail address: andrepaga23@live.it 
In order to make urban areas more resilient, a novel risk reduction approach based on a strategic development of urban and infrastructural systems has been proposed within the last Sendai Protocol developed in 2015 based on the resilience concept. The Sendai Protocol also foresees building the capacity to learn and thus anticipate the effect of a catastrophe, which is a substantial element for increasing resilience against natural hazards [1].

For this purpose, the introduction of the term resilience has an important role, however the term itself is interpreted in many different ways depending on the field of science. This concept is "essential" to describe the functionality of the communities, infrastructures or any other type of systems under the effect of hazard. Based on the United Nations Office for Disaster Risk Reduction (UNISDR), disaster risk management resilience is used to describe "ability of a system, community or society exposed to hazards to resist, absorb, accommodate, adapt to, transform and recover from the effects of a hazard in a timely and efficient manner, including through the preservation and restoration of its essential basic structures and functions through risk management". In this context resilience is also being actualized by the EU Commission to ensure appropriate planning and preparation for disaster risk management and sustainable development [2].

Secondly, the paper outlines the main characteristics of the financial instruments called resilience bonds (collateral), highlighting, in particular, the reference values inherent to the risk that affect the insurance premium, if any, and the uncertainty related and inherent in the contract itself.

In the third instance, the paper highlights the possible consequences on the calculation of the risk and, likewise, of the premium, in relation to the construction of mitigating infrastructures.

Subsequently, entering the focus of the paper, the authors highlight the possible correlations between the decrease in risk following construction of a mitigation infrastructure and the issue on the financial market of resilience bonds linked to the immovable assets de quibus.

In the fourth instance, the authors examine the supranational legislation inherent to Sustainable Energy and Climate Action Plan (SECAP), highlight the guidelines dictated by the European Union paying attention to a systematic framing of a financial system such as resilience bonds [3] in relation to the variations of adaptation and mitigation of environmental risk referred to in the same SECAP.

In particular, the authors, through a quantitative study projection with related cost benefit analysis, seek to first outline the financial effects in the issue of bonds, highlight the costs inherent to the infrastructures and perform a summary of the operation as a whole from one point from an economic and social point of view.

The motivations that led the authors to carry out such analysis are inherent, on the one hand, to the social implications in the sense that greater protection of assets and better awareness of the problem referred to natural disasters allow the community to be aware of the risk. Secondly, it was carried out in order to highlight the possible financial variations in the sense in which the implementation of mitigative works partially limits the damage to the same assets.

Third, the assets covered by recursive insurance, at the end of the mitigation implementation, are naturally subject to a greater interest on the market. Ultimately, any ex post damages, on the one hand limited as highlighted above, with a view to implementing a resilience bond, would be distributed among heterogeneous subjects, avoiding imbalances on the public economy. The cost-benefit analysis is necessary from a public law perspective in the sense in which, according to the authors, the proposed model, for the protection of the res 
publica, must be purely addressed to the public administration and, thus, such a careful analysis is prodromal and factual for the implementation and activation of the relevant bodies.

The choice to carry out an in-depth analysis of the possibility of implementing the method and of the practical application of the model to flood risk mitigation mainly concerns the seriousness of the damage caused by the aforementioned hazard on the territory of Italy, as can be seen from the last report called the yearbook of environmental data relating to 2017 . The year 2017 was marked by fourteen paroxysmal events characterized by high quantities of rain often concentrated over the course of a day, which caused "flash floods" (sudden floods) in both urban and rural areas.

\section{TABLE 1. HaZARD / GDP AND ALlOCATED Sums ASSESSMENT AND ANALYSIS}

\begin{tabular}{|c|c|c|c|c|c|}
\hline $\begin{array}{l}\text { Event } \\
\text { period }\end{array}$ & County & $\begin{array}{l}\text { Victims and } \\
\text { missing } \\
\text { persons }\end{array}$ & Resources to restore, $€$ & $\begin{array}{l}\text { Total estimated } \\
\text { damage / GDP, } \\
\%\end{array}$ & $\begin{array}{l}\text { Funds allocated with } \\
\text { executive provisions, } €\end{array}$ \\
\hline $\begin{array}{l}15- \\
20 / 1 / 17\end{array}$ & Molise & 0 & $€ 99006314$ & 0.005784 & $€ 5400000$ \\
\hline $\begin{array}{l}15- \\
18 / 1 / 17\end{array}$ & Abruzzo & 29 (landslide) & $€ 77200000$ & 0.045103 & $\begin{array}{l}€ 42536321.59 \\
\text { (DPC funds } \\
€ 63000000 \\
\text { (funds for Soil Defence } \\
\text { Interventions -Reg. Abruzzo) }\end{array}$ \\
\hline $\begin{array}{l}21- \\
23 / 1 / 17\end{array}$ & Sicilia & 1 & $€ 30879578$ & 0.001804 & $€ 8000000$ \\
\hline $\begin{array}{l}22- \\
25 / 1 / 17\end{array}$ & Calabria & 0 & $€ 108758274$ & 0.006354 & $\begin{array}{l}€ 22000000 \\
\text { (DPC) } \\
€ 56000000 \\
\text { (Fiscal Law 2018) }\end{array}$ \\
\hline $\begin{array}{l}26- \\
28 / 4 / 17\end{array}$ & $\begin{array}{l}\text { Friuli } \\
\text { Venezia } \\
\text { Giulia }\end{array}$ & 0 & $€ 1600000$ & 0.000093 & $\begin{array}{l}€ 800000 \\
\text { (Ministry of the Environment } \\
\text { and Protection of the } \\
\text { Territory and the Sea) } \\
€ 485000 \\
\text { (Italian civil protection - } \\
\text { Friuli Venezia Giulia) }\end{array}$ \\
\hline $25 / 6 / 17$ & Veneto & 0 & $€ 12312842$ & 0.000719 & $€ 6700000$ \\
\hline $28 / 6 / 17$ & Lombardia & 0 & $€ 200000$ & 0.000011 & \\
\hline $5 / 8 / 17$ & Veneto & 1(landslide) & $\begin{array}{l}€ 12312842 \text { (adding } \\
\text { damages occurred on } \\
28 / 6 / 17 \text { ) }\end{array}$ & 0.000719 & $€ 6700000$ \\
\hline $8 / 8 / 17$ & Valle d'Aosta & 0 & $€ 7887156$ & 0.00046 & $€ 3000000$ \\
\hline & & & & & $\begin{array}{l}€ 15570000 \\
\text { (DPC funds) }\end{array}$ \\
\hline $9-10 / 9 / 17$ & Toscana & 8 & $€ 56188554$ & 0.003282 & $\begin{array}{l}€ 20000000 \\
\text { (Toscana) }\end{array}$ \\
\hline $5-7 / 11 / 17$ & Campania & 0 & $€ 289037162.00$ & 0.016886 & \\
\hline $\begin{array}{l}11- \\
12 / 12 / 17\end{array}$ & $\begin{array}{l}\text { Emilia } \\
\text { Romagna }\end{array}$ & 0 & $€ 105000000$ & 0.006134 & $€ 10000000$ \\
\hline
\end{tabular}


Table 1 reflects information extracted from the Higher Institute for Environmental Protection and Research (ISPRA) website on some of the most severe hazards which have occurred; the analytical description [4] relating to the damage and effects to the ground of the flood events that occurred in 2017, the assessment of the overall damage compared to GDP, and most of all, the funds allocated with executive provisions.

Some salient features can be deduced from this explanatory and highly significant table.

First of all, the total quantified value $(€)$ of the damages occurred as a result of floods that occurred in Italy during the year 2017. The amount, truly significant, is greater than $€ 700000000$ and the importance of the value is reflected by the fact that the total national public budget is equal to approximately $€ 27000000000$. Therefore, the value of damages exclusively for flood damage was almost $3 \%$ compared to the entire allocated budget of the 2017 financial law.

The second focal point can be obtained from the sum of the respective values inherent in the ratio between estimated damage and GDP. The aforementioned value is equal to $0.1 \%$ of the GDP of the entire nation and is inherent, as already highlighted above, only to the damage caused by floods which occurred in one year. This result is also extremely worrying.

But it is the third result that proves to be the most upsetting for cost benefit analysis or for any other public economy study, i.e. the relationship between the amount provided by public administrations and resources to restore any assets.

In fact, by adding the value of the amounts paid by public bodies for the ex post reconstruction of assets damaged by floods, the amount is only equal to $€ 260191322$.

Therefore, the ratio between the value for the integral reconstruction of the assets and the loans is only $35.9 \%$ and, therefore, for over $60 \%$ of the value of the residual value of the assets, the administration was unable to carry out any reconstruction.

It is precisely from this elementary analysis that, in the authors' opinion, it no longer seems possible to think of a continuation of the classic method of contrasting against natural hazards, which is therefore capable of operating pro quota exclusively ex post.

The authors' perspectives are inherent to an implementation of urban resilience and the accounting and financial management of the risks of public administration assets

The conclusions pertain to the possible operational variations and effects of an application of the related insurance contract for mitigating constructions on the financial market, such as, for example cat bonds or preventive resilience bonds.

\section{Methodology}

The methodology proposed by the authors follows three guidelines:

- The first, preliminary, concerns a theoretical study of administrative and insurance regulations on the modality of stipulation of contracts between the public administration and private companies.

- The second concerns an engineering elaboration on urban resilience and, more particularly on flood risk. In particular this section involves a graphic projection of risk analysis.

- In the third instance, in the quantitative context, the authors propose the elaboration of a stylized quantitative model for a cost-benefit analysis, considering a traditional insurance scheme and a resilience approach with which the authors consider the opportunity of financing mitigative infrastructures. 


\section{FAILURE OF InSURANCE Systems Against NATURAL DisASTERS}

The starting point in the drafting of the paper is represented by the analysis carried out by the authors regarding the insurance systems against natural hazards in some of the more developed countries on the basis of 2019 IVASS report [5].

As can be seen from the Table below, the system, although in some cases, more capable of withstanding catastrophic events, is always fallacious in the dual meaning of application that the paper aims to highlight and implement, that is, primarily the ex-ante prevention and not therefore, merely the ex post reconstruction, and secondly, the division of costs into heterogeneous subjects and not already exclusively to be charged to public entities.

\section{TABLE 2. GENERAL FRAMEWORK OF FR/CH/UK/US INSURANCE SYSTEM AGAINST NATURAL HAZARDS}

\begin{tabular}{|c|c|c|c|c|}
\hline & France & Switzerland & UK & USA \\
\hline Hazards & $\begin{array}{l}\text { Floods, } \\
\text { earthquakes, } \\
\text { volcanic eruptions, } \\
\text { tsunamis }\end{array}$ & $\begin{array}{l}\text { Floods, landslides, } \\
\text { earthquakes }\end{array}$ & $\begin{array}{l}\text { Earthquakes, storms } \\
\text { and floods }\end{array}$ & $\begin{array}{l}\text { Specific policies for hurricanes, } \\
\text { storms, other specific policies for } \\
\text { floods and earthquakes. Flood } \\
\text { coverage: mandatory for } \\
\text { mortgages, with federal insurance } \\
\text { program (public-private } \\
\text { partnership) }\end{array}$ \\
\hline
\end{tabular}

\begin{tabular}{|c|c|c|c|c|}
\hline $\begin{array}{l}\text { Obligatory } \\
\text { nature }\end{array}$ & $\begin{array}{l}\text { System not } \\
\text { mandatory, but } \\
\text { insurance is } \\
\text { compulsorily } \\
\text { linked to a } \\
\text { widespread, basic } \\
\text { fire protection }\end{array}$ & $\begin{array}{l}\text { System not } \\
\text { compulsory, but for } \\
\text { many natural risks } \\
\text { insurance } \\
\text { compulsorily linked } \\
\text { to a very widespread, } \\
\text { basic fire protection }\end{array}$ & $\begin{array}{l}\text { System not mandatory. } \\
\text { Optional insurance } \\
\text { linked to relatively } \\
\text { widespread basic } \\
\text { coverages, generally } \\
\text { provided in case of } \\
\text { mortgages }\end{array}$ & $\begin{array}{l}\text { Floods: compulsory coverage in } \\
\text { flood risk areas and for buildings } \\
\text { covered by mortgages. Earthquake: } \\
\text { coverage not mandatory }\end{array}$ \\
\hline $\begin{array}{l}\text { System } \\
\text { governance }\end{array}$ & $\begin{array}{l}\text { Strong state } \\
\text { regulatory role, } \\
\text { unlimited public } \\
\text { economic } \\
\text { guarantee for the } \\
\text { main reinsurer }\end{array}$ & $\begin{array}{l}\text { Strong regulatory role } \\
\text { of the local cantonal } \\
\text { authorities. In most } \\
\text { cantons, insurance is } \\
\text { offered by a publicly- } \\
\text { owned company. }\end{array}$ & $\begin{array}{l}\text { No regulatory } \\
\text { intervention by the } \\
\text { state. No public } \\
\text { compensation foreseen } \\
\text { in case of natural } \\
\text { disaster }\end{array}$ & $\begin{array}{l}\text { Floods: role of the federal } \\
\text { government in determining risk and } \\
\text { tariffs. Fund grants subsidize } \\
\text { policies. Earthquake: Partnership in } \\
\text { California with the } \\
\text { California Earthquake Authority } \\
\text { CEA Fund which enjoys tax } \\
\text { benefits and grant-subsidized } \\
\text { policies }\end{array}$ \\
\hline $\begin{array}{l}\text { Role of } \\
\text { insurance } \\
\text { companies }\end{array}$ & $\begin{array}{l}\text { Hedging offer, } \\
\text { compensation } \\
\text { management, } \\
\text { creation of } \\
\text { dedicated reserves } \\
\text { in the financial } \\
\text { statements }\end{array}$ & $\begin{array}{l}\text { Insurance system } \\
\text { offers coverage and } \\
\text { manages } \\
\text { compensation, in the } \\
\text { form of a public } \\
\text { monopoly or under } \\
\text { free competition }\end{array}$ & $\begin{array}{l}\text { Hedging offer, } \\
\text { compensation } \\
\text { management, and } \\
\text { establishment of } \\
\text { dedicated reserves in } \\
\text { the financial } \\
\text { statements, which } \\
\text { might take advantage } \\
\text { of tax breaks }\end{array}$ & $\begin{array}{l}\text { Policies in collaboration with } \\
\text { various forms of partnership, where } \\
\text { applicable }\end{array}$ \\
\hline Reinsurance & $\begin{array}{l}\text { A state-guaranteed } \\
\text { reinsurer is } \\
\text { provided, with } \\
\text { freedom to operate } \\
\text { for other entities }\end{array}$ & $\begin{array}{l}\text { It is provided by } \\
\text { consortium systems } \\
\text { that associate public } \\
\text { and private insurers } \\
\text { separately }\end{array}$ & $\begin{array}{l}\text { Insurance companies } \\
\text { operate freely on the } \\
\text { market }\end{array}$ & $\begin{array}{l}\text { Free reinsurance market, also } \\
\text { issued cat bonds by the CEA fund }\end{array}$ \\
\hline
\end{tabular}




\section{SECAP ANd Covenant OF Mayors. New Perspectives}

This section aims to relate the perspective of a cost benefit analysis for recursive insurance contracts against natural hazards and the legislation relating to SECAP (former SEAP) and covenant of mayors

In December 2008, the EU adopted an integrated energy and climate change strategy which sets ambitious targets for 2020. The aim is to steer Europe on the right path towards a sustainable future by developing a low carbon economy based on energy efficiency [6].

The EU has set three key deadlines, defined respectively: "2020 package", "2030 package", "2050 package".

The 2020 package establishes the following objectives:

1. $20 \%$ reduction in greenhouse gas emissions compared to 1990 levels;

2. $20 \%$ of energy consumed in the EU is produced from renewable sources;

3. $20 \%$ improvement in energy efficiency.

The 2030 package defines the following objectives:

1. at least $40 \%$ reduction in greenhouse gas emissions compared to 1990 levels;

2. at least $27 \%$ of the energy consumed in the EU produced from renewable sources;

3. $27 \%$ improvement in efficiency energy [7].

The 2050 package sets the most ambitious goal, namely an $80 \%$ cut in emissions compared to 1990 and a so-called "low-carbon economy" implemented in every country in the European Union.

It should also be said that each nation belonging to the European Union has set its own targets for reducing emissions, which may even be higher than those set by the EU. To achieve these goals, it is clear how each economic sector must contribute to the reduction in emissions.

This document (SECAP) must be submitted within two years of the ratification of accession to the Covenant of Mayors by the City Council (for Italy) or the equivalent decision-making body (for foreign municipalities). The SECAP is divided into six sections presented hereafter, each of which refers to a specific implementation process:

Strategy: Definition of the goal of reducing $\mathrm{CO}_{2}$ emissions. The target can be set both in absolute terms and per capita reduction; the use of per capita reduction targets is used by cities that have a constant and / or rapid increase in population, so it is more complex and insignificant to set an absolute reduction target.

Emissions inventory: Definition of the final energy consumption of the municipality and the consequent $\mathrm{CO}_{2}$ emissions, divided by energy carrier and sector in the reference year. It is highly recommended that this year be the same as the one for which the intervention strategy is to be defined, to avoid difficulties in interpreting the results. Other important data to include are number of inhabitants, type of measurement unit that will be chosen (whether tonne $\mathrm{CO}_{2}$ or equivalent tonne $\mathrm{CO}_{2}$, which integrates the emissions of other greenhouse gases), and any notes on the method. Finally, the results are listed on the final energy consumption, on the supply of the same and on the total emissions. Two approaches are provided for the total calculation of emissions: the first is the so-called standard, defined by the IPCCC (International Panel Convention for Climate Change),

Mitigation actions: Description of the actions that are intended to mitigate emissions; also with assignment of budget, attribution of responsibility, forecast of timing and reduction. It is important to also include comparison scenarios; usually the "Business as Usual" scenario is used to analyse what the emissions trend would be like if no reductive action was taken, and it is compared with a scenario in which instead contrast actions have been taken. This type of processing is graphical and also allows you to see the estimated effectiveness of the initiatives, 
and to understand which can be the most effective in terms of cost / benefit ratios. The impact of the actions on its own time span is estimated (2020 or 2030). For each action planned for implementation, it is useful to give an estimate of its economic cost and effectiveness. Within this section it is also possible to insert the examples of excellence; i.e. emission reduction actions that have been particularly successful; these initiatives must be already concluded or in progress [8].

Scoreboard: To understand the sectors where the actions and the adaptation cycle prepared in the action plan have been successful. In other words, the scoreboard Framework serves to provide a snapshot of the progress of the adaptation process in which the local administration is placed, according to an evaluation of this type. It is a self-assessment; each administration will then give a vote based on what it considers complete at each phase of the process.

Risk and vulnerability: This section is dedicated to the assessment of climate risk in the area, with impact and related assessments. In this case, it is necessary to specify the year in which this assessment was made; in addition, it is necessary to specify the territorial area on which the risk and the method used are assessed. Indications are also given on particularly significant climatic hazards. In addition to the risk and climate vulnerability assessments, the potential effects that these criticalities can bring in the various sectors are indicated (for example: drop in tourism, risk of water shortages, etc.). This section is present only in the new SECAP.

Actions for adaptation: Illustrates the actions taken to adapt to climate change in various sectors, with an indication of investors (stakeholders) and costs. The various actions are described on the basis of sectors of intervention (e.g. in the construction sector, an adaptation action is the ban on building in places particularly at risk to flooding / landslides). This section is also present only in the new SECAPs [9].

Established to involve cities in the pursuit of the objectives of the European Union, the Covenant of Mayors is characterized by a multi-level governance model and is based on the shared vision according to which local administrations, together with private partners, can accelerate ambitious energy strategies that lead to a future with low greenhouse gas emissions. The initiative encourages its signatories to draw up action plans and to direct their investments towards mitigation and adaptation measures to climate change. Joining this initiative represents an opportunity for local authorities to consolidate their efforts to reduce greenhouse gas emissions in the area, benefit from European support and recognition, and exchange experiences with European counterparts. In addition, the Covenant of Mayors can be seen not only as an initiative related to the energy sector, but also as a way to develop sustainable measures that allow their cities to achieve better urban planning and socio-economic development [10]. Even if initially it was designed for large urban centres, the Covenant of Mayors did not place requirements on the size of the signatories: everyone can participate, from small municipalities to major metropolitan areas. Today the Covenant of Mayors, which became global in 2017, has over 7500 local and regional authorities active in 121 countries, which can take advantage of the strength of a multi-stakeholder movement worldwide and the technical and methodological support offered by various dedicated offices

Therefore, in the regulatory context of local public administrations, in anticipation of adherence to the Covenant of Mayors, the paper seeks to show and to highlight possible operational variations on risk mitigation, in particular against floods, for the negotiation and development of insurance contracts [11]. 


\section{CONCEPT OF INFRASTRUCTURAL RESILIENCE}

Due to the complexity and interdependency of infrastructure in urban areas, there is a higher risk to have cascading effects and also generate secondary effects in areas much further from the real flooded area [9], [10]. This is a key aspect to consider in order to minimize the secondary problems, such as financial and operative ones that are directly affecting the networks may have [10]. In order to make urban areas more resilient, a novel risk reduction approach based on a strategic development of urban and infrastructural systems has been proposed based on the resilience concept within the last Sendai Protocol developed in 2015 [10]. The Sendai Protocol also foresees building capacity to learn and thus anticipate the effect of a catastrophe, which is a substantial element for increasing resilience against natural hazards [14].

For this purpose, the introduction of the term resilience has an important role, however the term itself is interpreted in many different ways depending on the field of science. This concept is "essential" to describe the functionality of the communities, infrastructures or any other type of systems under the effect of hazards [15]. Based on the United Nations Office for Disaster Risk Reduction (UNISDR), disaster risk management resilience is used to describe "ability of a system, community or society exposed to hazards to resist, absorb, accommodate, adapt to, transform and recover from the effects of a hazard in a timely and efficient manner, including through the preservation and restoration of its essential basic structures and functions through risk management" [2]. In this context, resilience is also being actualised by the EU Commission to ensure appropriate planning and preparation for disaster risk management and sustainable development.

Some studies suggest that infrastructure resilience has a direct connection with the term resilience proposed by Holling and used in ecology [15]. This definition is generalized as the capacity of a system to absorb disturbances and to recover after a major disruption and to restart an activity on the territory [11].

Based on this, different methods have been proposed to assess resilience and the role of the infrastructural resilience within it. For instance, in the scientific work of Serre et al. [11] urban/engineering networks able to propagate flood risk are proposed overall urban resilience, understood and identified into 3 main capacities namely: resistance capacity, absorption capacity and recovery capacity. A similar approach for looking at resilience was proposed by Bruneau et al. [16] with the introduction of the "4Rs" (i.e. Robustness, Redundancy; Resourcefulness; and Rapidity), according to which resilience of specific systems is described by qualities of the system matching these 4Rs.

Such conceptual and (semi) quantitative model approaches based on the selection of a set of proper indicators can serve as the base for the development of a framework for assessing the effectiveness of specific mitigation and/or adaptation strategies.

\section{Insurance against Natural Disasters. The Reason behind its LIMITED SPREAD IN ITALY}

In this context, Italy stands out on the international scene for the management of damage from natural disasters entrusted almost exclusively to state intervention during the ex post reconstruction phase. This factor, together with the "cultural" reluctance of individuals to acquire protection against natural disasters, explains the scarce diffusion of insurance coverage for these events, which can be acquired as a supplement to fire insurance policies 
on homes. The reduced propensity of Italian families, compared to other European countries, to purchase non-compulsory, non-life coverage also contributes negatively [17].

The spread of insurance against natural disasters is higher for industrial and commercial buildings, but its level is still unsatisfactory. For example, the 2012 Emilia earthquake caused a lot of damage to the dense industrial fabric of companies in the area affected by the event. However, even on that occasion the contribution of insurance compensation to the costs for the reconstruction was modest (around $10 \%$ of the total costs, OECD 2017). While in the case in Italy the ratio between total damages and damages compensated by insurance was 10 to 1, during the 2005 hurricane Katrina, which happened in the United States, a country with a high degree of insurance coverage against natural disasters, the ratio was approximately equal to 3.5 [18].

In order to have an updated picture of the diffusion of the insurance instrument to protect itself against damage from natural disasters by homeowners, in the first months of 2017 the Italian Insurance Supervision Institute conducted a census survey [17], [18] with all the companies that on 30 September, 2016 would work on fire insurance field against fire the housing units located in Italy. The companies have reported the main characteristics of the individual contracts, including the possible extension of coverage to damage caused by earthquakes and floods. Fire coverage protects 12.2 million homes $(35.4 \%$ of the total similar properties in Italy). The percentage is extremely small compared to other EU countries.

As for Italy, as has already been analysed, there is no compulsory insurance on natural disasters and the implementation and level of policies covering damage from natural disasters are poor.

The current situation of the Italian insurance market for coverage against natural disasters sees the assets of private citizens not fully covered against disaster risks; only a limited part of medium-small companies is insured with specific policies covering earthquakes and floods; on the other hand, a significant part of medium-large companies is adequately insured against natural disasters, especially multinational companies.

According to Kunreuther [21], the scarce penetration of policies among private citizens is the result of a real disaster syndrome due to both distortions on the demand side and insufficient supply. In the following, we will analyse how the scarce diffusion of policies on a voluntary basis covering natural disasters is attributable to different types of causes: regulatory problems are added to the causes on the demand side and to the causes on the regulatory side.

In particular, with regard to the regulation referred to in public-private bargaining, the legislator never intervened precisely in outlining guidelines on these modalities.

In fact, as highlighted below, the stipulation of any insurance contract by a local authority must go through a rigorous discipline of public tender, as used in the broader context of public and administrative law [22].

Although the legislator has never provided for a specific discipline for the above type of insurance, this does not mean that this contractual scheme is prohibited by any law. Using a theoretical scheme and verifying what is referred to in the Italian and EU binding regulations, the authors have tried to outline the current operating methods to achieve a contracting and stipulation meeting point between public and private.

The point of interconnection between local authorities and insurance companies, in light of the results of the paper, can only be the covenant of mayors which, we would say, finally, grants greater autonomy to some bodies governed by public law. 


\section{FLOOD RISK AND RESILIENCE}

As mentioned urban population increase and the consequential rise of the increase complexity of the CI represent factors that amplify the level of local vulnerability [16], [17]. In fact, there is a direct connection of the natural hazard losses to the number of people and complex infrastructure living in areas prone to hazards.

Thus, the assessment of the Risk losses is not a trivial task since both the engineering dimension as well as the social impact should be evaluated. Generally, the Risk to natural disaster including flood is defined within the probability perspective in terms of occurrence time of a certain hazards, factored by the severity of its consequences [25], according to the following formula:

$$
\text { Risk }=\text { Probability } \cdot \text { Consequence }
$$

Thus, Risk represents a key instrument and criteria leading to flood zone management policy, land and infrastructural development planning [26]. It is thus evident the important role of the engineering dimension to assess the potential cost/benefit in terms of decreased flood risk level once a specific (or other engineering system) is strengthened and/or newly built.

Risk formula presents also other expended description on where the probabilistic dimension of the Hazard is then related to the Exposure and Vulnerability. Both aspects are related to the intrinsic propensity of a certain asset to be at Risk. Thus, the engineering aspect to understand the effects of a hazard of a certain magnitude is essential. This general formula is reported below:

$$
\text { Risk }=\text { Hazard } \cdot \text { Exposure } \cdot \text { Vulnerability }
$$

Within the proposed Risk assessment there the need to use GIS-based system on which hazard (e.g. flood), vulnerability and assets maps are combined through the use a weighing process and normalization.

This task has to be replicated for each climate-related impact [27].

In this way the flood risk assessment is translated in terms of potential loss and damages costs. This is most of time impossible to be done for each infrastructure and/or asset at risk due to data scarcity. In these way insurance companies' databases are often using proxies to overcome this bottleneck.

As reported by Kaspersen and Halsnes [28] Danish Insurance Company define a damage function and unit damage costs based on flood levels for different buildings during extreme precipitation. In this case health costs (based on number of people exposed to mixed rainsewage water) and expected costs for different rain patterns considering extremes climate event are calculated in monetary values as losses for each asset and damage costs.

Since quantitative and probabilistic approaches are not always possible to be used and converted into a monetary dimension (mostly in connection to the social dimension, the effectiveness of Risk Reduction scenarios through a Multicriteria Assessment (MCA) towards urban adaptation planning [29].

Normally with adaptation strategies are beneficial for the overall resilience of certain system and thus its risk reduction. According to [25] for physical systems can be identified in 2 types of measures namely hard and soft. The first referred to (semi)permanent installation within the area of the potential flood, the second ones are those relate to natural process for example like are tackling flood in terms of erosion decrease and or increase of roughness in the flooded areas [2], [11]. 
Despite the guidelines provide by Sendai Framework for strengthening resilience to disaster, several risk flood assessments have not fully implemented a resilience approach. Sometimes, only reduction measures to flood hazard are proposed as possible solution while in other only the perspective of the vulnerability is considered. Nevertheless, in both cases a range of solutions for maximum flood magnitude is offered. The main criticality is lying on not considering the time dependent concept of the resilience aspects such as the time of recovery.

Traditional flood risk analyses are mainly focused on hazard reduction and its impact as damages reduction in fact directly introducing structural and infrastructural measures. This approach is not addressing the attention to pre-flood hazard condition and recovery phase to return to the ex-ante situation.

There is a lack on real quantitative methods able to shave more tailored strategies to have more resilient infrastructure to flood resilience, and one of the main reasons is the because several disciplines and expertise should be involved (i.e. flood, resilience, and CI network interdependencies.

By using a resilience approach time dependency, such as recovery can be taken into account as and thus considering other characteristic component of the resilience such as robustness, redundancy and flexibility (see Fig. 1). While traditional approaches consider as the only utility function to be maximized the damage.

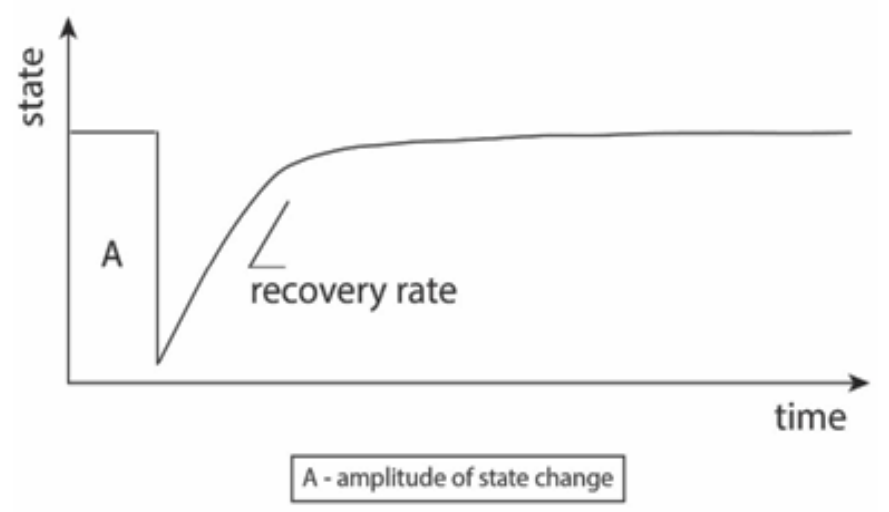

Fig. 1. System response to a shock [1].

The concept of resilience is also embedding the concept of state equilibrium and its threshold of stability, once that threshold is passed the recovery is not feasible. Fig. 2 highlights these aspects at different level of magnitude of a certain hazard and involving several components of the resilience.

For example, systems may need to be able to cope rigidly (resistance) to the most frequent hazards that they are exposed to or the hazard which causes the greatest damages and disruption (resilience). 


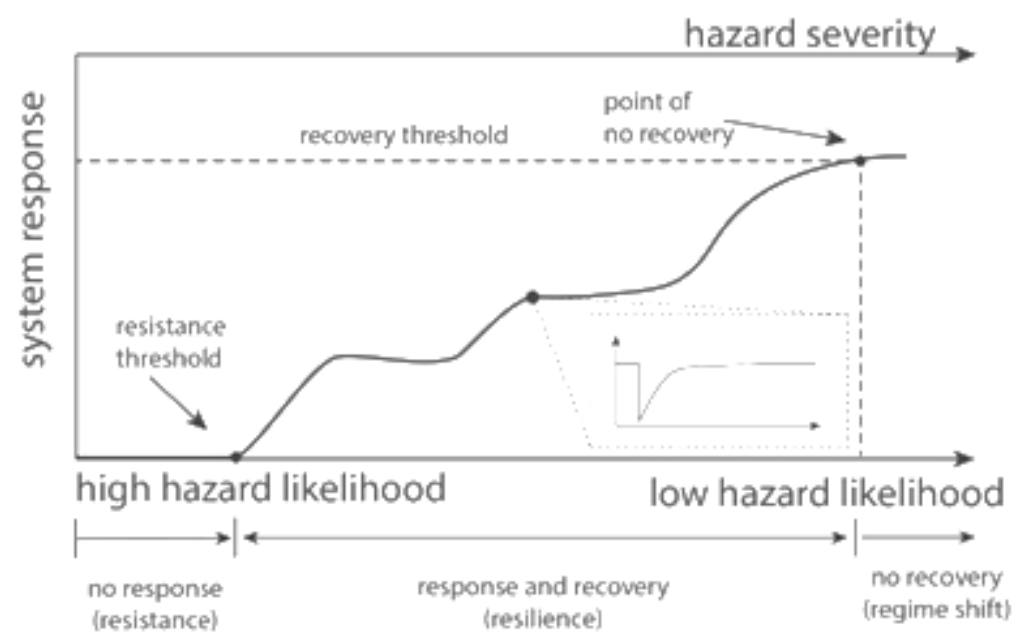

Fig. 2. System response as a function of disturbance magnitude [1].

Flood impacts are often quantified in terms expected annual damage (EAD) depending on evaluation of the exceedance probably related to certain hazard likelihood (Fig. 3).
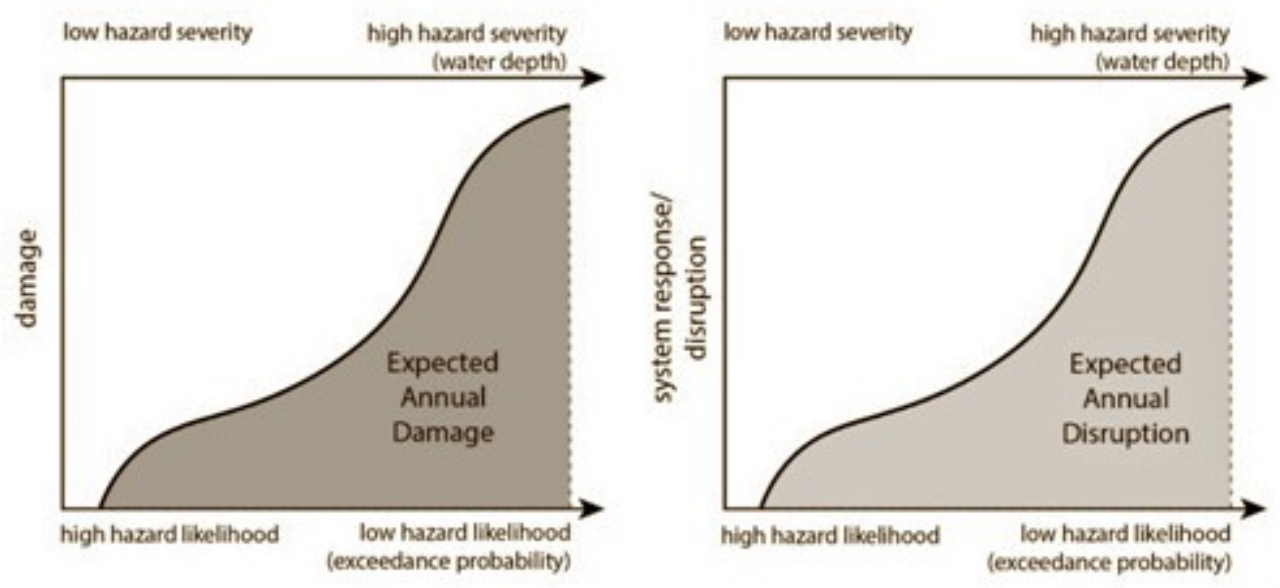

Fig. 3. Expected annual damage and expected annual disruption.

Moreover, the assessment of optimal and tailored strategies is related to the difficulty of the data availability.

Fig. 4 shows the effects on the application of CI resilient strategy applicable also to flood. 

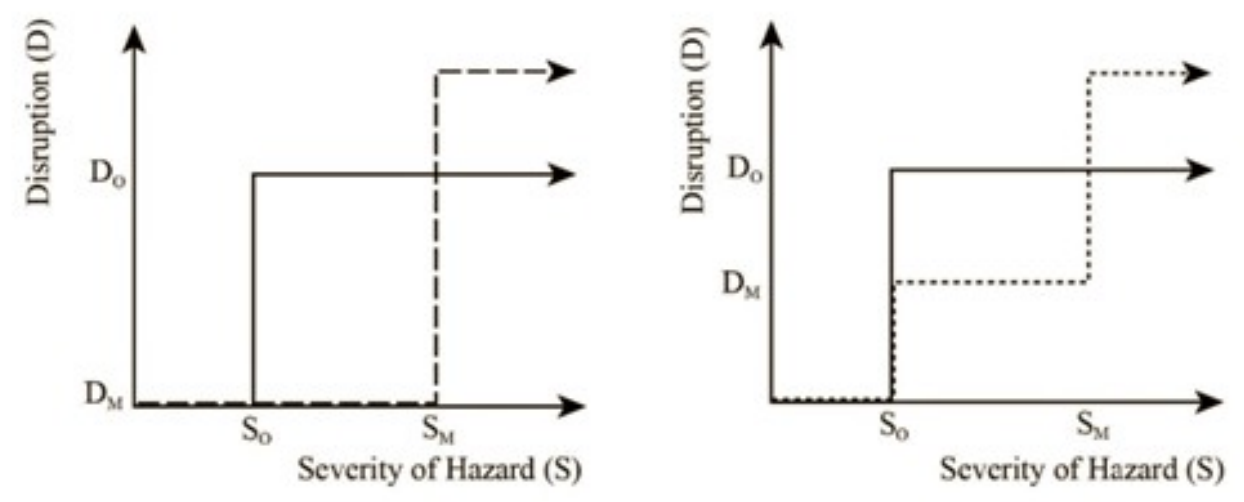

Fig. 4. Visualisation of the effect of resilience.

Data gathering is a key aspect on risk reduction of CI through a resilient strategy that should involve:

- Data collection from the gathering for CI networks;

- Flood hazard maps;

- Assessment of the exposure and vulnerability of CI to floods;

- Assessment of the cascading effects;

- Assess the recovery time.

It is essential to have create and inventory about the damages past events.

There are also other dimensions to be considered in the system response in terms of economic and social aspects in turn involving other vulnerability indicators.

In this context prevention measure like discouraging citizens from living in high-risk areas, or encouraging the uptake of mitigation measures has a great potential within the recovery strategy.

However, this aspect is still lacking on a real application due to lacks on existing legal frameworks to support these measures.

From the proposed approach on quantifying the reduction of Risk due to specific resilience measures it is possible to see how there is a need for the creation of an interdisciplinary and holistic approach.

\section{The Actuarial Quantitative Cost-Benefit Analysis for Flood RISK. INSURANCE OR RESILIENCE BONDS}

In this part of the paper, we introduce a stylized quantitative model for a cost-benefit analysis, considering a traditional insurance scheme and a resilience approach with which we may consider the opportunity of financing mitigative infrastructures [30].

The analysis has to be performed taking account of both the two viewpoints: one concerning the profit or loss account and the other the balance sheet, to which the mitigative infrastructures must be thought of as an additional value of the asset side.

Let consider that the flood risk could be expressed by the distribution of the claim amount in a fixed time unit, and that this risk must be faced throughout a fixed time horizon, at most even perpetual. 
Let $X$ be such r.v. with known density function and moments. Let consider a risk assessment based only on the first two moments of such r.v. $\mathrm{E}[X]=m_{1}$ and sigma $[X]=m_{2}$, such that insurance premium $P$ is a function of these two parameters $\mathrm{f}\left(m_{1}, m_{2}\right)=P$.

We can consider a finite time horizon $T$ (time units) or at least an infinite time horizon.

Assuming a fixed discount rate $\mathrm{r}$ and the relative discount factor $v=1 / r$, the actual total cost for flood risk insurance $C(T)$, is

$$
C(T)=P\left(1+v^{T}\right) / r
$$

in case of time horizon $T$ and

$$
C(\infty)=P / r,
$$

in case of infinite time horizon, that is a perpetual payment $P$.

Let consider a mitigative infrastructure with cost $K$ and a building time duration $S$. Let assume $S<T$. Let consider that after this infrastructure is built, the exposure to flood risk is reduced, i.e. we have a new claim r.v. $Y$ with the first two moments $E[Y]=n_{1}$ and $\operatorname{sigma}[Y]=n_{2}$, such that insurance premium is a function of these two parameters $\mathrm{f}\left(n_{1}, n_{2}\right)=$ $P_{1}$ for which it is $P_{1}<P$.

A resilience bond is composed by two parts, one relative to the insurance aspect and the other relative to infrastructure financing.

We can assume that for the insurance side the issuer has to pay a coupon equal to $P$ and for the financing side an additional coupon of $Q=g(K)$, till time $S$, which can be the bondmaturity.

So the actual total cost in case of a resilience bond approach, $D()$, is

$$
D(T)=(P+Q)\left(1+v^{S}\right) / r+v^{S}\left(1+v^{(T-S)}\right) P_{1} / r,
$$

in case of time horizon $T$.

$$
D(\infty)=(P+Q)\left(1+v^{S}\right) / r+v^{S}\left(P_{19} / r\right),
$$

in case of infinite time horizon, that is a perpetual payment $P_{1}$ after time $S$.

Therefore we can compare the total cost for the two approaches, $C()$ and $D()$, both for a finite and for an infinite time horizon. It is even an easy task performing a sensitivity analysis on the model parameters: $X, Y, r, K, \ldots$.

Some of them could be better and better be estimated using new data that arrives continuously.

So we can have full awareness of the cost-benefit analysis of using a classic insurance scheme or a more resilient approach financing the costs of the first time interval, till the mitigative infrastructure is ended, in our scheme time $S$, issuing a resilience bond with this maturity and with a coupon rate depending on the original risk measured by the premium $P$ and the additional part linked to the infrastructure cost $K$, which would serve both for risk coverage and for infrastructure financing.

\section{CONCLUSIONS}

Given the mostly quantitative/mathematical declination, the first conclusion concerns, among other things, the usefulness of recalling the need for an assessment of investments for mitigation, also in terms of lower risk coverage costs in the future, for public administrations. 
Secondly, it appears necessary to reiterate the absolute need for a desirably European, but at least national, platform to make the transfer of the risk outlined above to the financial markets fully operational.

Ultimately, in full compliance with what has been pre-written by the supranational treaties as well as by the Covenant of Mayors itself, it is fundamental to underline that the elements of the legislation that can govern all the steps of this process, should and could be agreed in a European way and not be the result of stunted harmonization of national regulations.

The proposed cost-benefit analysis highlights the possible implementation of the quantitative infrastructure resilience model and is subject to the need, extremely current in light of national regulations, to carry out a mathematical study prior to a political, business and financial choice such as that of a mitigative structure, and the related contractual insurance structure.

The final key point is to assess if the higher cost of a resilience bond, with the financing of mitigative infrastructures, could be convenient respect to a traditional insurance approach, i.e. only facing claims payments, for different time spans.

\section{REFERENCES}

[1] UN General Assembly. Resolution 69/283 of 23 June 2015. Sendai framework for disaster risk reduction 2015-2030. United Nations, 2015.

[2] Uniddr. World Conference on Disaster Reduction. Building the Resilience of Nations and Communities to Disasters. Geneva: UNDDR, 2005.

[3] Trærup S. L. M. Informal networks and resilience to climate change impacts: A collective approach to index insurance. Glob. Environ. Chang. 2012:22(1):255-267. https://doi.org/10.1016/j.gloenvcha.2011.09.017

[4] Eventi Alluvionali. Report 1. 2019:D. (in Italian) https://annuario.isprambiente.it/sys_ind/79

[5] IVASS. Report Analisi Trend Offerta (Offer Trend Analysis Report). Rome: IVASS, 2019. (in Italian)

[6] Alberti M. Politiche e strumenti di sostegno allo sviluppo delle fonti di energia rinnovabili. Casi di studio in paesi dell' Unione Europea (Policies and tools to support the development of renewable energy sources. Case studies in European Union countries.). 2010:95. (in Italian)

[7] De Botselier B. How the EU covenant of mayors and climate-adapt strengthen local climate policy-making. A Case Study of the City of Bruges. IED, 2019.

[8] Berghi S. Energy use in Urban Transport sector within the Sustainable Energy Action Plans (SEAPs) of three Italian Big Cities. Energy Procedia 2017:126:414-420. https://doi.org/10.1016/j.egypro.2017.08.193

[9] Blazquez J., et al. Economic policy instruments and market uncertainty: Exploring the impact on renewables adoption. Renewable and Sustainable Energy Reviews 2018:94:224-233. https://doi.org/10.1016/j.rser.2018.05.050

[10] Melica G., et al. Multilevel governance of sustainable energy policies: The role of regions and provinces to support the participation of small local authorities in the Covenant of Mayors. Sustainable Cities Society 2018:39:729-739. https://doi.org/10.1016/j.scs.2018.01.013

[11] Cinocca A., Santini F., Cipollone R. Monitoring methodologies and tools for the Sustainable Energy Action Plans to support the Public Administration. Energy Procedia 2018:148:758-765. https://doi.org/10.1016/j.egypro.2018.08.135

[12] Pescaroli G., Kelman I. How critical infrastructure orients international relief in cascading disasters. Journal of Contingencies Crisis Management 2017:25(2):56-67. https://doi.org/10.1111/1468-5973.12118

[13] Lhommes S., et al. Analyzing resilience of urban networks: a preliminary step towards more flood resilient cities. Natural Hazards and Earth System Sciences 2013:13:221-230. https://doi.org/10.5194/nhess-13-221-2013

[14] Serre D., Heinzlef C. Assessing and mapping urban resilience to floods with respect to cascading effects through critical infrastructure networks. International Journal of Disaster Risk Reduction 2018:30(B):235-2423. https://doi.org/10.1016/j.ijdrr.2018.02.018

[15] Holling C. S. Resilience and stability of ecological systems. Annual Reviews of Resource Economics 1973:4:1-23. https://doi.org/10.1146/annurev.es.04.110173.000245

[16] Bruneau D. A framework to quantitatively assess and enhance the seismic resilience of communities. Earthquake Spectra 2003:19(4):733-752. https://doi.org/10.1193/1.1623497

[17] Swiss Re-Sigma. Natural catastrophes and man-made disasters in 2013: large losses from floods and hail; Haiyan hits the Philippines. Zurich: Swiss Re, 2014. 
[18] Kunreuther H. C., Michel-Kerjan E. O. The Development of New Catastrophe Risk Markets. Annual Review of Resource Economics 2009:1(1):119-137. https://doi.org/10.1146/annurev.resource.050708.144302

[19] Statistico B. Bollettino Statistico 2012. Rome: Bank of Italy, 2012. (in Italian)

[20] Relazione sull'attività svolta dall'Istituto nell'anno 2017 (Report on the activity carried out by the Institute in 2017.). Rome: IVASS, 2018.

[21] Kunreuther H. Mitigation and Financial Risk Management for Natural Hazards. The Wharton School University of Pennsylvania Philadelphia, 2001.

[22] Asaro M., et al. 07 / 11 / 2017 - Le assicurazioni a copertura dei rischi degli enti pubblici e dei dipendenti pubblici tratto (07/11/2017 - Insurance covering the risks of public bodies and public employees tract.). Brescia: National Professional Association of Municipal and Provincial Secretaries, 2020. (In Italian).

[23] Roberts R. S. Economic Strategies for Coastal Disaster Risk-Reduction: A Case Study of Exmouth. Western Australia: Murdoch University, 2012.

[24] Botzen W. J. W., Van Den Bergh J. C. J. M. Insurance against climate change and flooding in the Netherlands: present, future, and comparison with other countries. Risk Analysis 2008:28(2):413-426. https://doi.org/10.1111/j.15396924.2008.01035.x

[25] Rumson A., et al. Coastal risk adaptation: the potential role of accessible geospatial Big Data. Marine Policy 2017:83:100-110. https://doi.org/10.1016/j.marpol.2017.05.032

[26] Filatova T. Veen A. Microeconomic Motives of Land Use Change in Coastal Zone Area: Agent Based Modelling Approach. Twente: University of Twente, 2006.

[27] Bertoldi P., et al. Guidebook "How to develop a Sustainable Energy and Climate Action Plan (SECAP)": PART 2 Baseline Emission Inventory (BEI) and Risk and Vulnerability Assessment (RVA). Luxembourg: European Union, 2018.

[28] Kaspersen P. S., Halsnæs K. Integrated climate change risk assessment: a practical application for urban flooding during extreme precipitation. Climate Services 2017:6:55-64. https://doi.org/10.1016/j.cliser.2017.06.012

[29] EEA. Urban adaptation to climate change in Europe 2016. Transforming cities in a changing climate. No 12/2016. Luxembourg: Publications Office of the European Union, 2016.

[30] Bellieri dei Belliera A., et al. Flood risk insurance: the Blockchain approach to a Bayesian adaptive design of the contract. 2019. 